Jurnal Keperawatan Padjadjaran

ISSN 2338-5324 (print)

ISSN 2442-7276 (online)

Online di http://jkp.fkep.unpad.ac.id

DOI : $10.24198 / \mathrm{jkp}$

\title{
An Exploration of Nurses' Experience of Family Presence During Resuscitation in Intensive Care Setting
}

\author{
Ni Putu Wahyu Ariani ${ }^{1}$, Yanny Trisyani' ${ }^{2}$, Titin Mulyati ${ }^{3}$ \\ ${ }^{1,2}$ Faculty of Nursing, UniversitasPadjadjaran, Bandung, Indonesia, \\ ${ }^{3}$ RSUP Hasan Sadikin, Bandung, Indonesia \\ Corresponding Email: yanny.trisyani@unpad.ac.id
}

Received: 02-09-2020 Revised: 04-03-2021 Accepted: 08-03-2021

\begin{abstract}
The family presence during resuscitation (FPDR) has received wide support to be implemented in the ICU.The implementation of FPDR has positive impacts on family satisfaction. However, some of the nurses' opinion still not agree on implementation of FPDR in ICU. This research therefore utilized phenomenological approach to gain descriptive explanation regarding this phenomenon. The purpose of this study is to explore thenurse's experiences in the implementation ofFPDR in the ICU. This research was conducted on the year 2020 and qualitative phenomenological approach was utilized for this research. Ten (10) ICU nurses have participated in this study and in-depth interview was employed for data collection. Data analysis is conducted using Colaizzi. Result of this research areexplained in 6 themes which describe the phenomenon of nurses' experience onfamily presence during recusitation, as follows: (1) Decisions on family; (2) From burdened to selfconfident; (3) Families enhancing teamwork; (4) The bereaved family disrupts the CPR process; (5) Feels of ignoring patiets' family and (6) Expectingthe family be accompanied by staff nurse.From a nurse's perspective, the implementation of FDPR has a positive impact on patients, families and on the ICU nurse team. However, this also has an unpleasant impact on ICU nurses, especially if the nurse is not ready for the practice. Therefore, policy support and training for nurses are needed in its implementation.
\end{abstract}

Keywords: Family presence, intensive care, nurse's experience, phenomenology. 


\section{Introduction}

The concept of Patient Family Centered Care is to involve families in all aspects of health service delivery including the presence of the family during Cardiac Pulmonary Resuscitation (CPR) (Abdar, Educator, Rafiei, \& Tbc, 2016). Family presence during resuscitation (PFDR) is the presence of a patient's family member at the scene where resuscitation is condected, so the family may see the cardiopulmonary resuscitation process(Salmond, Paplanus, \& Avadhani, 2014). FPDR is supported by $94 \%$ to $100 \%$ of patient family members, where patients and family members view FPDR as their right(Powers \& Candela, 2016). The Family perspectives on FPDR vary widely. Families feel their presence will provide support, they want to see that everything has been done, families do not want patients to die alone, and they want to participate in deciding when to stop resuscitation and to declare martyrdom at death (Alshaer et al., 2017)

The view of the family who does not want to be present during the CPR process, the reason is because theey feels they may disturb and the family is worried. Their presence interferes the resuscitation process, the family feels afraid and feels unable to help (Alshaer et al., 2017).

FPDR has a positive impact on family members. Research by Pasquale, Pasquale, Baga, Eid, and Leske (2010)shows that anxiety, satisfaction, and well-being of the family are better in the group that witnessed CPR procedure than in the control group who did not witness the CPR process. Research by Jabre and Borron (2014) also shows that Post Traumatic Stress Disorder (PTSD), anxiety, and depression are significantly lower in family members who have the opportunity to be present during the resuscitation process compared to those who are absent.

FPDR has gain support from families and has a positive impact on family members. However, not all critical care nurses who often involved in CPR procedure are supportive and some of the nurses do not support family attendance during CPR. Nurses who support the practice of family attendance, arguing that family presence is the right of the patient and the family (Chapman, Watkins, Bushby, \&
Combs, 2012; Porter, Grad Cert Ed, Cooper, \& Taylor, 2015; Lederman, Baird, Dong, Leong, \& Pal, 2017). Another reason is that the presence of the family benefits the family, namely: relieving family worries and calming down, increasing family satisfaction, feeling the family is contributing to the care of their loved ones, being able to understand what is happening to their loved ones, understanding the severity, family presence allows relatives to know the patient's critical condition, helps dispel doubts by recording everything that is possible, relatives feel closeness and help the grieving process (Hassankhani, Zamanzadeh, Rahmani, Haririan, \& Porter, 2017; Twibell, Siela, Riwitis, Neal, \& Waters, 2017; Barreto, Garcia-Vivar, Mitchell, \& Marcon, 2018).

Nurses who do not support family attendance during CPR because: (1) additional pressure would be placed on staff members, feeling pressure to continue resuscitation, staff performance is scrutinized and supervised by families, increased stress and anxiety among CPR team members, impaired team focus resuscitation and staff want to avoid feelings of insecurity in resuscitation practices (Wacht, Dopelt, Snir, \& Davidovitch, 2010; Chapman et al., 2012; Porter et al., 2015, Abdar et al., 2016; Hassankhani et al., 2017; Lederman et al., 2017; Barreto et al., 2018); (2) family presence can result in family members interfering during the procedure, prolonging resuscitation efforts and the potential for families to discontinue resuscitation(Bashayreh, Saifan, Batiha, Timmons, \& Nairn, 2015; Porter et al., 2015; Twibell et al., 2017; Hassankhani et al., 2017; Zali, Hassankhani, Powers, Dadashzadeh, \& Rajaei, 2017;Waldemar \& Thylen, 2018; Barreto et al., 2018); (3) concerns regarding verbal and physical attacks if they allow the family to witness resuscitation(Stefan, Kaltwasser, Rothaug, \& Albarran, 2010; Wacht et al., 2010; Bashayreh et al., 2015; Lederman et al., 2017); (4) there is insufficient support for family members and limited space in the resuscitation area (Chapman et al., 2012;Hayajneh, 2013; Lederman et al., 2017; Barreto et al., 2018).

The above studieshas been suggested that that research on FPDR has been conducted in many countries, while in Indonesia, FPDR research is still very limited. Due 
to differences in cultural backgrounds, educational levels, understanding and religion as well as nurses' practices in carrying out family attendance, of course, will provide a different picture in Indonesia. Therefore, this research is important, to be carried out in an Indonesian context. Internationally, FPDR has received recognition that FPDR has a positive impact on family members who are present during CPR and the families has supported FPDR practices. However, the nurse' opinion of FPDR, has indicated that some nurses support the practice and, some are still not supportive. Therefore, research with qualitative phenomenological approach is needed, to gain understanding of the phenomena experienced, felt and seen by nurses' participants regarding the family presence during the CPR process in the ICU.

The purpose of this study was to explore the experiences of nurses on family presence during the CPR process in the Intensive Care Unit (ICU) of the regional hospital, Bali. The result of the study has the potential, to provide better understanding regarding the nurses' perspective on family presence during resuscitation.

The result of this study is also expected to provide data and information for the development of policy and standard operational procedure of the implementation of FPDR in critical care setting.

\section{Method}

The research utilized qualitative approach descriptive phenomenology which aims to describe the nurse's experience of family presence during the CPR process in the ICU Room. Giorgi (2009) and Moustakas (1994) in Creswell (2014) suggest that phenomenological research is a research design that rooted from philosophy and psychology where researchers describe the human experience regarding a certain phenomenon as described by the participants. The study was conducted at the ICU at the District Hospital, Bali. The data collection of this study began, after ethical clearance from the health research ethics committee of the Universitas Padjadjaran number: 219/UN6.KEP/EC/2020 has been obtained.
Subsequently, the permission for conducting this research was also obtained from the Director of District Hospital, Bali. Then, the researcher accessed prospective participants through director of nursing and the head of nursing at the critical care setting

Participants of the study were selectedusing the purposive sampling based on inclusion criteria: (1) Nurses who have conducted CPR in the ICU which attended by the family more than once time; (2) Nurses with at least have 2 years working experience in the ICU; (3) Minimum educational background 3 years nursing diploma. Prospective participants were given information about the study and signed an informed consent if they agreed to participate in this study. Data collection was conducted through in-depth interviewson Mar 5-April 30, 2020 and it was conducted in the ICU head nurse' office. The interview was audio recorded with the participants permission and the data was then transcribed verbatim. The interviews'duration were about 30 to 60 minutes. The participants in this study were ten (10) ICU nurses who were met the inclusion criteria. Data analysis used the Colaizzi method.

The criteria for maintaining the quality of this study were derived from Lincoln and Guba (1985) regarding the rigor and trustworthiness of the qualitative study through credibility, transferability, dependability, and confirmability.In this study, credibilitywas achieved through member checking where the themes obtained from the participant's interviews are conveyed back to the participants to get feedback regarding the theme formulated by the researcher.In this case, almost all of the participants recognized the theme conveyed by the researcher as significant issues of what they felt. Except for participant 9, who has suggested that she only feels some significat issues, namely in the theme: decision is on the family, feels of ignoring patiets' family, and expecting the family be accompanied by staff nurse. Transferabilitywas achieved through applying the phenomenological method in this study, so that the results could be applied to other situations which have nearly similar context. Dependability was achieved through implementing the descriptive phenomenological method and 
conducted data analysis with Colaizzi (1978) approach, so that a rich description of the phenomenon under study could be obtained. Confirmabilitywas achieved through the implementation of phenomenology research method, and the achievement of credibility, transferability, and dependability in this study (Lincoln \& Guba, 1985).

\section{Results}

The nurses' experiences in implementing family presence during resuscitation in the ICU setting at Hospital in Bali is described in the 6 themes: (1) Decisions is on the family; (2) From burdened to self confident; (3) Families enhancing teamwork; (4) The bereaved family disrupts the CPR process; (5) Feels ignoring patients'family and (6) Expecting the family accompanied by staff nurse.

\section{Decision on family}

The first theme in this study is "Decisions on Family" with the sub-theme of giving choices to families which are obtained from the participants' expressions that when the patient's condition worsens, the participants give the option of offering whether to attend or not to attend CPR. As stated by P1 and P9. "... So far, for me personally ... even if there are patients who get worse ... we keep calling the family ... we educate ... it's up to them to watch our actions or come out ..." (P1.12)

"... the patient is experiencing a deterioration ... we are family KIE ... then if the family wants to wait for the patient to take action ... we will invite ... then if not ... we'll also invite ... (P9.10)

\section{From burdened to self-confident}

This theme was obtained from the experiences of participants who expressed the participants "feelings at the beginning of doing CPR, attended by their families until the participants' experiences increased.

Participant 1 expressed feelings of nervousness and discomfort, but with increasing experience of doing CPR in the presence of family, participants felt calm and could control their emotions. Here is P1's expression:
".... Honestly... the first time.. I did that RJPO... . I continued to have my family..... nervous sometimes... sometimes... when we had done the right thing... looked at it like that... there was still a sense uncomfortable too..." "(P1.19)

"... At first, I was nervous ... to face the patient's family ... especially if the patient started to complain ... or did aggressive actions ..." (P1.25)

"....... And... now... because I am used to taking action witnessed by my family... we just do it according to the procedure with a feeling of calm..." (P1.23)

"... but ... over time because we often face ... conflicts like that ... over time I can control ... our emotions ... control emm ... our feelings of empathy ... concentrate on the patient ... as well as ... by concentrating on the patient and still facing... umm... family emotions... family conflicts..." "(P1.26)

At the beginning of carrying out CPR in the presence of the family, participant 3 expressed feelings of pressure and felt a psychological burden, but with the increased experience of doing CPR in the presence of the family, P3 felt that they could be trained to provide IEC during the CPR process and felt more motivated and excited about doing CPR. Here's a P3 quote:

".....While doing CPR accompanied by family ... for the first time it was done CPR accompanied by a family ... it felt like I was depressed .. very depressed .. nervous ... (P3.10)

"... When we first did CPR, especially in the ICU ... if we were seen by several families, we felt a psychological burden to do CPR .." (P3.1)

"... At first it was really hard to pay attention to it ... but over time after doing CPR several times accompanied by the family ... we can be trained to do IEC during the CPR process ... so that the psychological burden of the family can be more accepting ... (P3.32)

"... We did CPR in the ICU several times ... we met several patients ... we did CPR with family assistance ... over time it became a motivation ... what is the name ... enthusiasm for the team to save this patient .. Moreover, being accompanied by family .. it becomes a spirit .... "(P3.13) 


\section{Families enhancing teamwork}

The next theme in this research is "Families enhancing teamwork" with the sub-theme Cooperation between teams is better. This theme is derived from the experience of participants who feel that the presence of a family during CPR affects team performance. As stated by P5:

“... keep on ...the positive side ... we are as a resuscitation team ... our actions are more organized ... more systematic ... in carrying out resuscitation actions ..." (P5.11)

The same thing was also expressed by participant number 7 . The following was the statement of participant 7 below:

".... Another positive thing... there is family assistance during resuscitation... we work as a team... can be more systematic andorganized according to the existing Standard Operating Procedure .. (P7.5)

\section{The bereaved family disrupts the CPR process}

Another experience expressed by participants in this study was "The bereaved family disrupts the CPR process", where participants see for themselves the emotional response of the family who accompanies the patient when the family witnesses the CPR process, such as the patient's family screaming hysterically, the family hopes the patient must live, the family tends to fainted and family cried. Participants felt that the family response was disturbing the CPR efforts.

"... If the results are not as expected.... the patient's family screams ... the denial stage or does not accept ... it also disturbs us as health workers .. "(P4.27)

The same thing was also expressed by participant number 7 and 8 . The following is the statement of participant 7 and 8 below:

"... There were also families screaming ... even fainting ... it really made our concentration break ..." (P7.11)

"... A less cooperative family ... when doing resuscitation ... he cries too hysterically which is also very disturbing when we do resuscitation .... (P8.8)

\section{Feels of ignoring patients' family}

The fifth theme is "Feels of ignoringpatients' family " with the sub theme of neglecting family psychological situation. This theme is derived from the experience of the participants that when doing CPR, the participants ignore the family psychology.

"... While the family ... umm ... I don't know if the family cries .. whether he accepts it ... we ignore it..emm ... you can say we ignore the psychological and emotional impact of the family ... because we focus on saving the patient .." (P5.24)

Participants also shared similar experiences with P6. The following is the statement of participant 6 below:

"... No one accompanies the family ... or calms the family ... we are busy with our respective duties as a CPR team to save patients ... so we focus on patients ..." (P6.17)

\section{Expecting the family be accompanied by staff nurse}

The next theme is "Expecting the family to be accompanied by professional staff " with the sub-theme of requiring other professional staff. This theme is the hope of the participants with the existence of other professional staff who help participants to accompany the family when the participants focus on doing CPR on patients, so that the families present at CPR are there to accompany and calm and provide explanations of every action during the CPR process. The following is the expression of participant 3 below:

"... Indeed in several times we have RJP ... there needs to be something like that ... someone explains what we are doing ... like a professional nurse is also important ... but so far we have also... can handle the psychological burden of the patient's family .. (P3.32)

The same thing was also expressed by participant number 4 . The following is the statement of participant 4 below:

“... Also I hope ... besides there are people or teams who prepare and carry out their respective duties ... here also I hope for one more person to help prepare or inform the patient's family from the beginning of the action we take ... until the end ..." (P4. 38)

In this study it was also revealed that 9 participants (P1, P2, P3, P4, P6, P7, P8, P9 and $\mathrm{P} 10)$ supported family presence during CPR and only 1 participant (P5) did not support family presence during CPR. 
"...This means that in essence ... that I support ... the existence of a family ... watched us take action or a family was in the room when the patient was taken ..." (P1.45)

The same is expressed by P7. Here's the P7 expression:

"... In my opinion ... seen from the positive and negative sides that I experienced and I feel ... I feel more on the positive side.... so I support the presence of the family during CPR ... (P7.37)

Different experiences are expressed by P5. Here is P5's expression:

"... If seen from the positive and negative impacts that I have had and I have felt ... I don't really support my family when we do resuscitation ..." (P5.46)

\section{Discussion}

The nurse participants explained that when the patient's condition worsened, the nurse participants would gave the choices to the family, to attend or not attend in the CPR process for the patient. Critical care nurses also advocate for patients and families in making treatment planning decisions including the implementation of palliative care and end of life care(AACN, 2015). The ENA and AACN recommend that health care agencies develop written protocols (policies and procedures) for regulating family attendance practices by including the following components in the protocol: (1) describing the benefits of family attendance from the perspective of patients, family members, and health care providers; (2) establish criteria for assessing family members so that patient care is not interrupted or delayed; (3) screen family members before offering options (for example, excluding those who show emotional distress, anger, drunkenness or altered mental status); (4) offer options and support for family members when they choose not to attend; and (5) assign family facilitators to consult with the health care team to get consensus and an appropriate timing and to support family members before, during and after CPR (Pankop, Chang, Thorlton, \& Spitzer, 2013)

According to the IPFCC (2010), the role of nurses in the PFCC concept, namely: (1) Nurses listen to and respect the perspectives and choices of patients and families, (2) Nurses communicate and share complete and unbiased information with patients and families so that families receive information timely, complete and accurate to participate effectively in care and decision-making, (3) Nurses encourage and support patients and families to participate in care and decisionmaking at their chosen level, and (4) Patients, families, care practitioners health and health care leaders collaborate in the development, implementation and evaluation of policies and programs in research, facility design and in professional education and in care delivery.

Based on the description above, it can be concluded that the participants have implemented the components of the FPDR Standard Operating Procedure recommended by ENA and AACN, although currently there is no FPDR Standard Operating Procedure in the hospital. Participants have also performed their role as educators or communicators by communicating and sharing complete and unbiased information with patients and families so that families receive timely, complete and accurate information

At the beginning of the participants doing CPR, attended by their families, the participants felt that there was a feeling of pressure, a feeling of discomfort and a feeling of burden. The results of this study are in accordance with the results of research by Wacht et al. (2010) showing that most staff members oppose FPDR on the grounds of concerns about family criticism, additional pressure to be exerted on staff members, fear of lawsuits and fear of hurting family feelings. This study is in line with the research of Porter et al. (2015) which involved 347 respondents who found that $17 \%$ of staff did not support FPDR because they felt uncomfortable with family presence or felt monitored, there was fear of litigation or concerns about violating patient confidentiality and prolonging resuscitation efforts. Research by Chapman et al. (2012) revealed that the reasons for staff not supporting family attendance include (1) disrupting the resuscitation process, (2) feeling pressure to continue resuscitation because performance is being monitored, (3) limited space in the resuscitation area, (4) no adequate support for family members of specialized professional staff. 
The increasing experience of doing CPR in the presence of the family, caused the participants' feelings to change from feeling overwhelmed to feeling confident in doing CPR. Five participants, namely P2, P3, P6, $\mathrm{P} 7$ and $\mathrm{P} 8$ expressed feelings of comfort from the increasing experience of doing CPR in the presence of their families. Participant 1 revealed that they feel calmer now even though they are supervised by their family. P2 said he felt more comfortable working. Participants also felt that the increased experience of doing CPR in the presence of the family was also felt by the participants to increase the ability to think critically and be more systematic, more responsible, better trained to giveinformation during the CPR process, feel motivated to correct the shortcomings of the first experiences that were carried out, be able to control emotions and feelings of empathy.

Self-confidence is an attitude or belief in one's own abilities, so that you are not too anxious about taking action, feel free to do things according to your wishes and responsibilities for your actions, are polite in interacting with others, have a boost in achievement and can get to know own strengths and weaknesses. The formation of self-confidence is a process of learning how to respond to various stimuli from outside of itself through interactions with the environment (Lauster, 2012). Selfconfidence is influenced by several factors, namely self-concept, self-esteem, education and experience (Ghufron \& Risnawati, 2010). Experience plays an important role in increasing emotional care for critical nursing and only nurses who have knowledge and high confidence about the CPR process can provide emotional care to the family (Connell \& Landers, 2008).

Based on the description above, the researcher can conclude that the emergence of participants' self-confidence is due to an adaptive process with increasing experience of doing CPR in the presence of the family. To increase self-confidence, participants should do CPR more frequently attended by their families.

The theme "Families enhance teamwork" was lifted from the experiences of participants who revealed the impact of having a family on teamwork. P1 and P4 revealed that teamwork would be better with the presence of family. Participants 1, P5, P7, P8 and P10 revealed that the presence of a family during resuscitation causes teamwork to be better, more systematic and organized in accordance with the existing SPO and is more coordinated. The results of this study are in line with the research of Gomes, Dowd, and Sethares (2019), which identified that most nurses $(92 \%)$ had experienced resuscitation witnessed by their families and most of them had positive attitudes about the benefits and results of resuscitation witnessed by families. The results showed that nurses did not believe that family attendance was too distressing for the family or that the resuscitation team's performance would be negatively affected.

Based on the description above, it can be concluded that family presence can also have a positive impact on teamwork. Teamwork becomes better, more systematic, coordinated and orderly by implementing CPR procedures in accordance with the existing Standard Operating Procedure.

Another experience expressed by participants in this study was "The bereaved family disrupts the CPR process", where participants see for themselves the emotional response of the family who accompanies the patient when the family witnesses the CPR process, and participants felt that the family response was disturbing the CPR efforts. The results of this study are in accordance with the research of Bashayreh et al. (2015)who conducted an exploratory qualitative study of 31 health professionals in 11 critical areas in 6 Jordanian hospitals, indicating that there may be a traumatic psychological effect on families due to witnessing traumatic resuscitation on their loved ones. Research by Hassankhani et al. (2017), Zali et al. (2017), Twibell et al. (2017), Waldemara and Thylen (2018), and Barreto et al. (2018) revealed that family presence will be painful for them and families feel depressed. Another study revealed that nurses did not agree with the implementation of FPDR in adults and nurses because they thought FPDR had many weaknesses where family members became depressed (Zali et al., 2017). WaldemaraandThylen (2018) expressed concern that families intervene during resuscitation, it is too painful for them 
that there is a strong consensus that there should always be a dedicated healthcare professional to care for the family.

Chapman et al. (2012) conducted a crosssectional study of 221 doctors and emergency room nurses to investigate the perceptions of emergency department staff about familywitnessed resuscitation, it was found that staff did not support family presence, one of which was family presence which resulted in disruption of the resuscitation process. This study is supported by Leung and Chow (2012) that the presence of a family during CPR results in chaotic resuscitation. This is in line with the results of Hayajneh(2013) study which showed $75 \%(n=102)$ agreed that family members are very likely to interfere with the resuscitation process. Research with similar results, namely research by Bashayreh et al. (2015), Porter et al. (2015), Twibell et al. (2017), Hassankhani et al. (2017), Zali et al. (2017), WaldemaraandThylen (2018), and Barreto et al. (2018) who showed that family presence could result in family members interfering during the procedure, prolonging resuscitation efforts and the potential for families to discontinue resuscitation.

Based on the description above, it can be concluded that the bereaved family needs information about the actions taken to the patient, the actual condition of the patient and the progress of the patient's condition, so that it requires health workers who have special skills to become effective communicators.

Another experience revealed was the negative attitude of the participants, namely ignoring the psychologicalimpact of the family accompanying the patient. All participants revealed that so far the participants did not pay attention to family feelings, both emotionally and psychologically, no one accompanied the family or calmed the family and no one gave explanations about the actions that were being carried out during CPR. Participants can only provide information before and after carrying out CPR actions. This is because the participants are more focused on saving patients and the limited number of team members who already have their respective roles.

A study conducted by Jabre et al. (2013 )of 570 family members, in which the intervention group received emotional and psychological support from experienced staff who were not part of the resuscitation team. The results showed that PTSD and anxiety disorders were lower in the group supported by experienced staff than in the group that did not receive emotional and psychological support during resuscitation. This study is supported by Soleimanpour, Tabrizi, Rouhi, Golzari, and Mahmoodpoor (2017) a study was conducted in Iran on 133 family members of patients, the intervention group $(\mathrm{n}=74)$ and the control group $(n=59)$. In the intervention group, a nurse who did not participate in the resuscitation was responsible for supporting the patient's family psychologically based on the developed protocol. The results showed that depression, anxiety and PTSD were significantly lower in the nurse-accompanied group.

Based on the description above, it can be concluded that the participants experienced a dilemma between making efforts to save patients or providing psychological support to their families. While family support is also important for preventing depression, anxiety and PTSD. Other professional staff are needed to assist the family or there is a division of tasks in the resuscitation team, some of which are assigned to assist the family.

All participants hope that there will be other professional staff who help participants to accompany the family when the participants focus on doing CPR on the patient, so that the families who are present at CPR are there to accompany and calm and provide explanations of every action during the CPR process. Powers and Candela (2017) in this study emphasizes the need for dedicated people serving as Family Support Person (FSP) to meet family needs so as to allow the team to focus on patient care. Family support person (FSP) is a role assigned to certain health care providers who do not have responsibility for direct patient care during resuscitation and are specifically assigned to initiate interventions to help families, provide emotional and psychosocial support (Abdar et al., 2016). This research is supported by research by Barreto et al. (2018) which suggests having people who qualify as facilitators. The role of a facilitator was identified as a strategy to prepare the family at the bedside of the patient and support the 
family before, during and after resuscitation.

Based on the concepts and descriptions above, the researchers concluded that one of the strategies for the successful implementation of FPDR practice is a dedicated person serving as a Family Support Person (FSP) to meet family needs by providing emotional and psychosocial support, thus enabling the team to focus on patient care. The FSP is a role assigned to a specific healthcare provider who has no responsibility for direct patient care during resuscitation.

The limitation of this study is that this studywas conducted during the COVID-19 pandemic. It had an impact that interviews were conducted with participants and researchers both used masks and kept their distance, so that researchers had a little difficulty observing the facial expressions of the participants. However, this can be overcome by focusing more on voice recordings which are employed as the main data source for this research.

\section{Conclusion}

The phenomenon of the livedexperience of nurses onthe implementation of FPDR were described in the six (6) themes: the decision is in the family; the nurse feels burdened initially but felt confidentwith increasing experience; the family presence has enhanced the teamwork; the presence of grieved and angry family often disrupted the nursing work; the nurse felt ignoring the patient's family; and expectedthe family be accompanied by a staff nurse.

From the ICU nurse's perspective, the implementation of FDPR has a positive impact on patients, families and on the ICU nurses' team. However, this experience also has created an unpleasant impact on ICU nurses, especially if the nurse was not ready for the practice. Therefore, policy support and training for the ICU nurses are needed in its implementation.

\section{Conflict of Interests}

The author states there is no conflict of interest in this study

\section{References}

AACN. (2015). Scope And Standards For Acute And Critical Care Nursing Practice. AACN Critical Care Publication.

Abdar, M. E., Educator, N., Rafiei, H., \& Tbc, A. D. (2016). Iranian nurse attitudes towards the presence of family members during CPR. 438 British Journal of Cardiac Nursing September, 11(9), 438-443. http:// dx.doi.org/10.12968/bjca.2016.11.9.438

Alshaer, A., Alfaraidy, K., Morcom, F., Alqahtani, W., Alsadah, Z., \& Almutairi, A. (2017). Saudi Family Perceptions of Family Witnessed Resuscitation in the Adult Critical Care Setting. Saudi Critical Care Journal, 1(4), 113-117. https://doi.org/10.4103/sccj. sccj

Barreto, M. S., Garcia-Vivar, C., Mitchell, M., \& Marcon, S. S. (2018). Family presence during resuscitation in emergency departments: professionals attitudes in Brazil. International Nursing Review, 1-10. https://doi.org/10.1111/inr.12490

Bashayreh, I., Saifan, A., Batiha, A., Timmons, S., \& Nairn, S. (2015). Health professionals 'perceptions regarding family witnessed resuscitation in adult critical care settings. Journal of Clinical Nursing, 24(6), 2611-2619. https://doi.org/10.1111/ jocn. 12875

Chapman, R., Watkins, R., Bushby, A., \& Combs, S. (2012). Family-witnessed resuscitation: Perceptions of nurses and doctors working in an Australian emergency department.ISRNEmergency Medicine, 2012, 1-10. https://doi.org/10.5402/2012/369423

Colaizzi, P. F. (1978). Phychologycal research as the phenomenologist views it. In R. Vaile \& M. King (Eds.). Existential Phenomenological Alternatives for Psychology, 48-71. Oxford University Press.

Connell, E. O., \& Landers, M. (2008). The importance of critical care nurses ' caring behaviours as perceived by nurses and 
Ni Putu Wahyu Ariani: An Exploration of Nurses’ Experience of Family Presence During Resuscitation

relatives. Intensive and Critical Care Nursing, 24, 349-358. https://doi.org/10.1016/j. iccn.2008.04.002

Ghufron, M. N., \& Risnawati, R. S. (2010). Teori-Teori Psikologi (Psychological Theories) . Cetakan I (Edition I). Yogyakarta: Ar- Ruzz Media.

Gomes, B. D., Dowd, O. P., \& Sethares, K. A. (2019). Attitudes of community hospital critical care nurses toward familywitnessed resuscitation. American Journal Of Critical Care, 28(2), 142-149. https://doi. org/10.4037/ajcc2019162

Hassankhani, H., Zamanzadeh, V., Rahmani, A., Haririan, H., \& Porter, J. E. (2017). Family presence during resuscitation: A double-edged sword. Journal of Nursing Scholarship, 49(2), 127-134. https://doi. org/10.1111/jnu.12273

Hayajneh, F. A. (2013). Jordanian professional nurses' attitudes and Experiences of having family members present during cardiopulmonary resuscitation of adult patients. Critical Care Nursing Quarterly 36(2), 218-227. https://doi.org/10.1097/ CNQ.0b013e31828414c0

Jabre, P., Belpomme, V., Azoulay, E., Jacob, L., Bertrand, L., Lapostolle, F., ... Ph, D. (2013). Family presence during cardiopulmonary resuscitation. The New England Journal O F Medicine, 368(11), 1008-1018. https://doi. org/10.1056/NEJMoa1203366

Jabre, P., \& Borron, S. W. (2014). Offering the opportunity for family to be present during cardiopulmonary resuscitation: 1-year assessment. Intensive Care Medical, 40(7), 981-987. https://doi.org/10.1007/s00134014-3337-1

Lauster, P. (2012). Tes Kepribadian. Terjemahan oleh D. H. Gulo (Personality Test. Translated by D. H. Gulo). PT. Bumi Aksara.

Lederman, Z., Baird, G., Dong, C., Leong, B. S. H., \& Pal, R. Y. (2017). Attitudes of Singapore Emergency Department staff towards family presence during cardiopulmonary resuscitation. Clinical Ethics, 12(3), 124-134. https://doi. org/10.1177/1477750917706175

Leung, N. Y., \& Chow, S. K. Y. (2012). Attitudes of healthcare staff and patients family members towards family presence during resuscitation in adult critical care units. Journal of Clinical Nursing, 21, 2083-2093. https://doi.org/10.1111/j.13652702.2011.04013.x

Pankop, R., Chang, K., Thorlton, J., \& Spitzer, T. (2013). Implemented family presence protocols: An ntegrative review. Journal of Nursing Care Quality, 28(3), 281-288. https:// doi.org/10.1097/NCQ.0b013e31827a472a

Pasquale, M. A., Pasquale, M. D., Baga, L., Eid, S., \& Leske, J. (2010). Family presence during trauma resuscitation: Ready for. The Journal of TRAUMA: Injury, Infection, and Critical Care, 69(5), 1092-1099. https://doi. org/10.1097/TA.0b013e3181e84222

Porter, J. E., Grad Cert Ed, G. D., Cooper, S. J., \& Taylor, B. (2015). Family presence during resuscitation ( FPDR ): A survey of emergency personnel in Victoria, Australia. Australasian Emergency Nursing Journal, 18(2), 98-105. https://doi.org/10.1016/j. aenj.2014.12.003

Powers, K. A., \& Candela, L. (2016). Family presence during resuscitation: Impact of online learning on nurses' perception and self-confidence. American Journal Of Critical Care, 25(4), 302-309. https://doi. org/10.4037/ajec2016814

Powers, K. A., \& Candela, L. (2017). Nursing practices and policies related to family presence during resuscitation. Dimensions of Critical Care Nursing, 36(1), 53-59. https:// doi.org/10.1097/DCC.0000000000000218

Salmond, S. W., Paplanus, L. M., \& Avadhani, A. (2014). Using systematic reviews to guide decision making about family-witnessed resuscitation. Journal of Peri Anesthesia Nursing, 29(6), 480-490. https://doi. org/10.1016/j.jopan.2014.07.011 
Soleimanpour, H., Tabrizi, J. S., Rouhi, A. J., Golzari, S. E. J., \& Mahmoodpoor, A. (2017). Psychological effects on patient's s relatives regarding their presence during resuscitation. Tabriz University of Medical Sciences, 9(2), 113-117. https://doi.org/10.15171/ jevtr.2017.19

Stefan, K., Kaltwasser, A., Rothaug, O., \& Albarran, J. (2010). Family witnessed resuscitation - experience and attitudes of German intensive care nurses. British Association of Critical Care Nurses, 15(5), 241-250. https://doi.org/10.1111/j.14785153.2010.00405.x

Twibell, R., Siela, D., Riwitis, C., Neal, A., \& Waters, N. (2017). A qualitative study of factors in nurses' and physicians' decisionmaking related to family presence during resuscitation. Journal of Clinical Nursing, 27(1), 320-334. https://doi.org/10.1111/ ijlh.12426

Wacht, O., Dopelt, K., Snir, Y., \& Davidovitch, N. (2010). Attitudes of Emergency Department Staff toward Family Presence during Resuscitation. Israel Medical Association Journal, 12(6), 366-370.

Waldemar, A., \& Thylen, I. (2018). Healthcare professionals ' experiences and attitudes towards family- witnessed resuscitation: A cross-sectional study. International Emergency Nursing, 1-8. https://doi. org/10.1016/j.ienj.2018.05.009

Zali, M., Hassankhani, H., Powers, K. A., Dadashzadeh, A., \& Rajaei, R. (2017). Family presence during resuscitation: A descriptive study with Iranian nurses and patients family members. International Emergency Nursing, 34, 1-6. https://doi.org/10.1016/j. ienj.2017.05.001 